\title{
DAMPAK PEMBANGUNAN JEMBATAN GENTALA ARASY BAGI MASYARAKAT SEKITAR KAWASAN.
}

\author{
Oleh : \\ *) Prima Audia Daniel \\ **) Dosen Tetap STIE Muhammaadiyah Jambi
}

\begin{abstract}
Abstrak
Pariwisata merupakan salah satu sektor strategis dalam pembangunan, yang mampu memberikan sumbangan bagi perekonomian meskipun tidak secara langsung. Pembangunan kawasan atau tempat wisata tentu memberikan dampak positif bagi masyarakat sekitar demikian yang terjadi pada kawasan pariwisata Jembatan Gentala Arasy. Dalam penelitian ini saya ingin menganalisis apakah pembangunan jembatan gentala arasy memberikan dampak positif bagi perekonomian masyarakat sekitarnya. Dalam penelitian ini saya menggunakan metode survei secara langsung yang kemudian di lanjutkan dengan analisis kualitatif dalam bentuk narasi dan tabulasi. Pada penelitian ini saya menggunakan 38 dengan persentase 10 persen dari jumlah populasi sampel yang ada.

Hasil analisis menunjukkan dengan dibangunnya tempat wisata Jembatan Gentala Arasy mampu memberikan dampak positif bagi perekonomian masyarakat sekitar yang terlihat terciptanya lapangan pekerjaan, pergerseran jenis pekerjaan dan peningkatan jumlah pendapatan masyarakat secara umum.

Kata Kunci : Dampak pembangunan jembatan Gentala Arasy

\section{Pendahuluan}

\subsection{Latar Belakang}

Pariwisata merupakan salah satu sektor strategis dalam pembangunan. yang mampu memberikan sumbangan bagi perekonomian melalui peningkatan kesejahteraan masyarakat. Berkembangnya priwisata tentu memberikan dampak baik secara langsung maupun tidak langsung bagi masyarakat disekitarnya. Dampak yang dirasakan masyarakat tersebut bisa berupa manfaat sosial ekonomi dan bahkan meningkatnya indeks kebahagiaan. Pembangunan jembatan gentala arasy merupakan tempat pariwisata yang dibangun dan dijadikan sebagai ikon pariwisata di Jambi. Selain sebagai ikon Jambi tentu memberikan dampak pada sosial ekonomi pada masyarakat.

Dengan adanya pembangunan tersebut dalam kesempatan saya ingin meneliti mengenai dampak sosial ekonomi dari pembangunan tempat wisata jembatan gentala arasy. Adapun tujuan dari penelitian ini adalah : (1) Bagaimana dampak perekonomian masyarakat sekitar dengan adanya pembangunan tempat wisata gentala arasy (2) Berapa besar dampak pembangunan Jambatan Gentala Arasy terhadap peningkatan pendapatan masyarakat sekitarnya.
\end{abstract}




\section{Tinjauan Pustaka}

Pariwisata adalah berbagai macam kegiatan wisata yang didukung berbagai fasilitas serta layanan yang disediakan oleh layanan yang disediakan oleh masyarakat, pengusaha, pemerintah, dan pemerintah daerah.

Kegiatan wisata sendiri adalah manusia yang melakukan perjalanan outbound (keluar dari lingkungan asalnya) untuk tidak lebih dari lebih dari enam bulan, dan tidak sedang dalam urusan berdagang atau lainnya (Hakim, 2004). Oran yang melaksanakan kegiatan pariwisata disebut wisatawan. Wisatawan erat kaitannya dengan pariwisata. Menurut Burkart dan Mendik (dalam Ross, 1998), wistawan memiliki empat ciri utama yaitu; (1) Wisatawan adalah orang yang melakukan perjalanan dan tinggal sementara di tempat tujuan; (2) Tempat tujuan wisatawan berbeda dengan tempat tinggal dan tempat kerjanya seharihari, karena itu kegiatan wisatawan tidak sama dengan kegiatan penduduk yang berdiam dan bekerja di tempat tujuan wisatawan; (3) Wisatawan bermaksud pulang kembali ke tempat tinggalnya dalambeberapa hari ataupun beberapa bulan karena wisata bersifat sementara atau jangka pendek; (4) Wisatawan melakukan perjalanan bukan untuk menetap di tempat tujuan atau bekerja mencari nafkah. Sedangkan menurut Cohen (dalam Ross) 1998) bahwa wisatawan adalah seorang pelancong yang melakukan perjalanan atas kemauan sendiri dan untuk sementara waktu saja, dengan harapan mendapat hal-hal baru.

\section{Sarana dan Prasarana Pariwisata}

Prasarana pariwisata adala semua fasilitas yang memungkinkan agar sarana pariwisata dapat hidup dan berkembang serta dapat memberikan pelayanan kepada masyarakat untuk memenuhi kebutuhan mereka yang beraneka ragam. Berapa jenis prasaran pariwisata antara lain ; (1) Prasarana Transportasi (pengangkutan) : yaitu prasarana yang dapat membawa wisatawan dari tempat tinggalnya ke daerah tujuan wisata; (2) Prasarana Komunikasi : yaitu sarana yang dapat mendorong wisatawan mengadakan perjalanan jarak jauh dengan adanya sistem komunikasi di daerah tujuan wisata. Seperti tersedianya jaringan komunikasi, telepon, kantor pos, dan lain-lain; (3) Kelompok yang termasuk utilities : yang termasuk dalam kelompok ini adalah penerangan listrik, persediaan air minum bersih, sistem irigasi, dan lain sebagainya; (4) Prasarana Sosial : yaitu semua faktor yang menunjang kemajuan atau menjamin prasarana perekonomian yang ada; (5) Sistem Pendidikan : yaitu adanya lembagalembaga pendidikan yang mengkhususkan diri dalam pendidikan kepariwisataan; (6) Pelayanan 
Kesehatan : perlunya koordinasi oleh Dinas Pariwisata setempat dengan dengan instansi terkait dalam memberikan pelayanan kesehatan terhadap wisatawan yang berkunjung; (7) Faktor keamanan : yaitu pelayanan dan fasilitas yang dapat memberikan rasa aman dan nyaman terhadap wisatawan. (Yoeti 1996).

Sedangkan sarana pariwisata adalah perusahaan-perusahaan yang memberika pelayanan kepada wisatawan, baik secara langsung dan tidak langsung dan hidup serta kehidupannya banyak bergantung pada kedatangan wisatawan. Sarana pariwisata dapat dikelompokkan menjadi tiga, yaitu : (1) Sarana Pokok Kepariwisataan : yaitu perusahaan yang hidup dan kehidupannya sangat bergantung kepada arus kedatangan orang yang melakukan perjalanan wisata; (2) Sarana pelengkap kepariwisataan : yaitu perusahaan-perusahaan atau tempat-tempat yang menyediakan fasilitas untuk rekreasi yang mestinya tidak hanya melengkapi sarana pokok kepariwisataan, namun yang terpenting adalah untuk membuat wisatawan semakin lama tinggal di suatu daerah tujuan wisata; (3) Sarana penunjang kepariwisataan : yaitu perusahaan yang menunjang sarana pokok dan pelengkap pariwisata yang berfungsi tidak hanya membuat wisatawan lebih lama tinggal pada suatu daerah tujuan wisata, tetapi fungsi yang lebih penting adalah agar wisatawan lebih banyak mengeluarkan atau membelanjakan uang mereka di tempat yang dikunjunginya. (Yoeti 1996).

\section{Teori Pengembangan Pariwisata}

Pengembangan suatu objek wisata sebagai daerah tujuan wisata (destination), harus memperhatikan lima unsur penting agar wisatawan dapat merasa puas dalam menikmati perjalanan wisatanya, lima unsur destinasi wisata tersebut meliputi ;(1) Daya tarik dan atraksi wisata : Merupakan pusat dari industri pariwisata yang mampu menarik wisatawan untuk berkunjung. Biasanya wisatawan tertarik pada suatu destinasi karena suatu ciri khas tertentu; (2) Fasilitas : Fasilitas cenderung mendukung bukan mendoorong pertumbuhan dan cenderung berkembang pada saat yang sama atau sesudah daya tarik berkembang (3) Infrastruktur : Daya tarik dan fasilitas tidak dapa tercapai dengan mudah jika belum ada infrastruktur dasar. Infrastruktur tersmasuk semua konstruksi baik di bawah maupun di atas tanah dari suatu wilayah atau daerah; (4) Transportasi : Informasi lengkap tentang fasilitas, lokasi terminal, rambu-rambu ke lokasi, dan pelayanan pengangkutan lokal di tempat tujuan harus tersedia untuk semua penumpang sebelum berangkat dari daerah asal; (5) Keramahtamahan : Wisatawan yang berada dalam lingkungan yang belum mereka kenal maka jaminan keamanan dan kenyamanan sangat penting, khususnya wisatawan asing (Spillane 1994). 


\section{Peran Serta Masyarakat dalam Kegiatan Pariwisata}

Peran sertamasyarakat dalam pariwisata dibag menjadi dua, yaitu : (1) partisipasi aktif : partisipasi yang dilakukan secara langsung baik secara perorangan maupun bersama-sama yang secara sadar ikut membantu program pemerintah dengan inisiatif dan reaksi mau melibatkan diri dalam kegiatan pengusahaan dan pembinaan rasa memiliki dari masyarakat; (2) partisipasi pasif : timbulnya kesadaran untuk tidak melakukan kegiatan kegiatan yang dapat mengganggu kegiatan wisata, baik terhadap wisatawan maupun atraksi wisata itu sendiri.

\section{Perubahan Kehidupan Masyarakat sebagai Dampak dari Pariwisata}

Menurut Cohen (dalam Hirawan 2008) dampak sosial pariwisata dapat dikelompokkan ke dalam sepuluh kelompok besar, antara lain : (1) dampak terhadap keterkaitan dan keterlibatan antara masyarakat setempat dengan masyarakat yang lebih luas, termasuk tingkat otonomi dan ketergantungan; (2) dampak terhadap hubungan interpersonal antar anggota masyarakat; (3) dampak terhadap dasardasar organisasi kelembagaan sosial; (4) dampak terhadap migrasi dari dan ke daerah pariwisata; (5) dampak terhadap ritme kehidupan sosial masyarakat; (6) dampak terhadap pola pembagian kerja; (7) dampak terhadap statifikasi dan mobilisasi sosial; (8) dampak terhadap distribusi pengaruh dan kekuasaan; (9) dampak terhadap meningkatnya penyimpangan penyimpangan sosial; (10) dampak terhadap bidang kesenian dan adat istiadat.

Cohen juga mengelmpokkan dampak ekonomi pariwisata, meliputi ; (1) dampak terhadap penerimaan devisa; (2) dampak terhadap pendapatan masyarakat; (3) dampak terhadap kesempatan kerja; (4) dampak terhadap harga-harga; (5) dampak terhadap distribusi manfaat/keuntungan; (6) dampak terhadap kepemilikan dan kontrol; (7) dampak terhadap pembangunan pada umumnya; (8) dampak terhadap pendapatan pemerintah.

\section{$B A B I I I$}

\section{Metode Penelitian}

Metode penelitian yang digunakan dalam penelitian ini adalah metode kualitatif dengan menggunakan data primer yang diperoleh secara langsung melalui survei dan wawancara yang diambil secara acak.

\section{Model Analisis Data}

Model analisis data yang digunakan dalam penelitian ini adalah model analisis deskriptif kualitatif yang bertujuan untuk melihat kondisi dan dampak adanya pembangunan Jembatan Gentala Arasy terhadap masyarakat di sekitar kawasannya. 


\section{Hasil Pembahasan}

Dalam penelitian ini kami menggunakan 50 kuisioner yang kami sebar secara acak pada responden di sekitar atau kawasan Jembatan Gentala Arasy. Dari 50 kuisioner tadi di sebar kepada 38 responden pelaku usaha di sekitaran jembatan gentala arasy yang terdiri dari 20 pedagang makanan dan minuman, 4 jasa sewa mainan, 1 pedagang mainan, 1 penjahit dan sewa pakaian adat, 3 pedagang pakaian, 1 pedagang aksesoris, 5 jasa sewa penyebrangan dengan ketek, serta 3 responden yang berasal dari penjaga parkir, dan sisa responden yaitu 12 pengunjung Jembatan Gentala Arasy.

Berdasarkan hasil analisis menunjukkan secara umum dengan dibangunnya jembatan gentala arasy maka dapat memberikan lapangan pekerjaan bagi masyarakat sekitar dan mampu meningkatkan pendapatan pada masyarakat sekitar.

\section{Dampak Perubahan mata pencaharian masyarakat disekitar Jembatan Gentala Arasy}

Dengan adanya Jembatan Gentala Arasy maka terlihat adanya pergeseran mata pencaharian masyarakat sekitar dimana yang semula masyarakat yang menjual makanan hanya sebesar 23 persen meningkat menjadi 52 persen. selanjutnya. Jenis pekerjaan sewa mainan meningkat menjadi 10,53 persen dari total responden yang sebelumnya belum ada. Sementara untuk jenis pekerjaan seperti buruh dan karyawan swasta yang sebelumnya ada menjadi tidak ada dan beralih ke jenis pekerjaan lain seperti jaga parkir, sewa baju, jual mainan dan pekerjaan yang lainnya. untuk lebih jelasnya dapat dilihat pada tabel 3.1 dan 3.2 sebagai perbandingannya.

Tabel Jenis pekerjaan responden sebelum di bangun Jembatan Gentala Arasy

\begin{tabular}{|l|l|c|c|}
\hline No & Jenis pekerjaan & Jumlah & Persentase \\
\hline 1 & Jual Makanan & 9 & 23,68 \\
\hline 2 & Jual Pakaian & 3 & 7,89 \\
\hline 3 & Jual Maian & 1 & 2,63 \\
\hline 4 & Jual Parfum & 7 & 18,42 \\
\hline 5 & Ngetek (Jasa Penyebrangan) & 2 & 5,26 \\
\hline 6 & Asisten Rumah Tangga & 1 & 2,63 \\
\hline 7 & Buruh & 2 & 5,26 \\
\hline 8 & Karyawan Swasta & 7 & 18,42 \\
\hline 9 & Petani & 1 & 2,63 \\
\hline 10 & Tidak Bekerja & 5 & 13,16 \\
\hline Jumlah & & 38 & 100 \\
\hline
\end{tabular}

Jika kita cermati ada salah satu mata pencaharian yang mengalami peningkatan dari sebelum adanya pembangunan Jembatan Gentala arasy dan setelahnya. Dimana mata pencaharian ini cukup beralih fungsi dari fungsi dasarnya yaitu jasa penyebrangan. Dimana 
sebelum di bangunnya Jembatan Gentala Arasy tersebut yang bekerja sebagai jasa penyebrangan dari total responden hanya 1 orang namun setelah adanya Jembatan Gentala Arasy bertambah jumlahnya menjadi 5 orang. dari hasil interview perubahan terjadi karena diakibatkan berubahnya peran utama jasa penyebrangan tersebut, yang semula berfungsi sebagai media tranportasi untuk aktivitas ekonomi namun saat ini berfungsi sebagai wahana pariwisata dan juga sarana transportasi.

Tabel Jenis pekerjaan responden setelah di bangun Jembatan Gentala Arasy

\begin{tabular}{|c|l|c|c|}
\hline No & \multicolumn{1}{|c|}{ Jenis pekerjaan } & Jumlah & Persentase \\
\hline 1 & Jual Makanan/minuman & 20 & 52,63 \\
\hline 2 & Sewa mainan & 4 & 10,53 \\
\hline 3 & Jualan Mainan & 1 & 2,63 \\
\hline 4 & Penjahit dan sewa Baju adat & 1 & 2,63 \\
\hline 5 & Jualan Pakaian & 3 & 7,89 \\
\hline 6 & Jualan Aksesories & 1 & 2,63 \\
\hline 7 & Ngetek & 5 & 13,16 \\
\hline 8 & Jaga Parkir Jumlah & 3 & 7,89 \\
\hline \multicolumn{2}{r}{} & & 100 \\
\hline
\end{tabular}

\section{Dampak Perubahan pendapatan responden di sekitar Jembatan Gentala Arasy}

Dalam hal peningkatan pendapatan, adanya pembangunan jembatan gentala arasy juga memberikan dampak yang signifikan bagi masyarakat sekitar. hal ini ditunjukkan daripergerakan jumlah kelompok pendapatan dari yang berpendapatan antara 1.000.000 sampai dengan 2.000.000 yang semula sebanyak 65,79 persen menurun menjadi 21.05 persen dan bergerak menjadi yang semula hanya 7,89 persen meningkat menjadi 63,16 persen pada kelompok pendapatan di atas 2.000.000. Ilustrassinya dapat dilihat pada tabel dibawah ini.

Tabel Pendapatan responden sebelum di bangun Jembatan Gentala Arasy

\begin{tabular}{|l|l|c|c|}
\hline No & Besar Penghasilan & Jumlah Responden & Persentase \\
\hline 1 & $<1.000 .000$ & 7 & 18,42 \\
\hline 2 & $1.000 .000-2.000 .000$ & 25 & 65,79 \\
\hline 3 & $>2.000 .000$ & 3 & 7,89 \\
\hline 4 & Tidak ada penghasilan & 3 & 7,89 \\
\hline Jumlah & 38 & 100 \\
\hline
\end{tabular}

Selanjutnya terlihat adanya penambahan lapangan pekerjaan dimana sebelum adanya pembangunan jembatan gentala arasy terdapat 3 responden yang masih belum memiliki pengahasilan atau pengangguran namun dengan adanya pembangunan jembatan tersebut tidak ada lagi yang menganggur atau sudah memiliki penghasilan. Ini menunjukkan bahwa adanya 
pembangunan jembatan tersebut mampu memberikan dampak positif terhadap perekonomian masyarakat sekitar.

Tabel Perubahan pendapatan responden di sekitar Jembatan Gentala Arasy

\begin{tabular}{|l|l|c|c|}
\hline No & Besar Penghasilan & Jumlah Responden & Persentase \\
\hline 1 & $<1.000 .000$ & 6 & 15,79 \\
\hline 2 & $1.000 .000-2.000 .000$ & 8 & 21,05 \\
\hline 3 & $>2.000 .000$ & 24 & 63,16 \\
\hline 4 & Tidak ada penghasilan & 0 & 0,00 \\
\hline Jumlah & 38 & 100 \\
\hline
\end{tabular}

Berdasarkan hasil penelusuran yang lainnya menunjukkan bahwa dari total responden mengatakan bahwa sebanyak 79 persen menyatakaan bahwa pembangunan Jembatan Gentala Arasy berdampak pada peningkatan pendapatan mereka sementara sebanyak 13 persen justru mengurangi pendapatan mereka dan sebanyak 8 persen tidak ada pengaruh terhadap pendapatan mereka.

Meski terjadi penurunan pendapatan pada masyarakat sekitar namun tidak terlalu signifikan hal ini dikarenakan pernurunan yang terjadi sebagai akibat bertambahnya penjual makanan. Dimana sebelum dibangunnnya tempat wisata tersebut penjual tersebut dapat lebih monopoli dalam berdagang dengan dibangunnya tempat wisata tersebut maka sistim penjualannya tidak dapat monopoli lagi sehingga pendapatan mereka menjadi berkurang. Namun disamping itu ada beberapa responden yang mengatakan bahwa ada atau tidak adanya tempat wisata jembatan gentala arasy tersebut tidak memberikan pengaruh terhadap pendapatan mereka. Hal ini dikerenakan jaran tempat berjualan mereka yang cukup jauh dari pusat tempat wisata tersebut meskipun masih dalam ruang lingkup tempat wisata Jembatan Gentala Arasy.

Tabel Perubahan pendapatan masyarakat setelah pembangunan Jembatan Gentala Arasy

\begin{tabular}{|l|l|c|c|}
\hline No & Jenis pekerjaan & Jumlah & Persentase \\
\hline 1 & Berkurangnya penghasilan & 5 & 13,16 \\
\hline 2 & Bertambah penghasilan & 30 & 78,95 \\
\hline 3 & Tidak ada pengaruhnya & 3 & 7,89 \\
\hline Jumlah & 38 & 100 \\
\hline
\end{tabular}

\section{Kesimpulan dan Saran}

Kesimpulan

Berdasarkan hasil analisa yang telah dilakukan maka dapat disimpulkan bahwa: 
1. Dengan adanya pembangunan Jembatan Gentala Arasy maka jenis pekerjaan masyarakat disekitar semakin sedikit namun persentase pengangguran semakin menurun.

2. Terjadi peningkatan pendapatan masyarakat sekitar Jembatan Gentala Arasy yang terlihat dari persentase besarnya jumlah pendapatan di atas 2 juta perbulan di bandingkan sebelum di bangunnya Jembatan Gentala Arasy.

3. Bahwa sebesar 78,95 persen masyarakat di sekitar Jembatan Gentala Arasy mengalami peningkatan pendapatan namun ada sebesar 13 persen yang mengalami penurunan pendapatan.

\section{Saran}

1. Dengan adanya pembangunan tersebut maka pemerintah perlu lebih memfasilitasi baik dalam sarana prasarana tempat pariwisata sehingga dapat meningkatkan kunjungan wisatawan dan berdampak pada peningkatan pendapatan masyarakat sekitar.

2. Pemerintah perlu menertibkan dan menetapkan aturan dalam pengelolaan wisata di kawasan Jembatan Gentala Arasy sehingga kegiatan wisata dan aktivitas kegiatan masyarakat disekitarnya dapat terlaksana dengan baik adil tanpa ada yang dirugikan.

\section{Daftar Pustaka}

Ismawan, Bambang. 2010. Keuangan Mikro Dalam Penanggulangan Kemiskinan dan Pemberdayaan Ekonomi Rakyat.Jakarta: Gema PKM

Saraswati. 2007. Peran Local Wisdom dalam Pengembangan Wilayah.Jurnal PWK Unisba, Vol 7, No 1, 13p.

Hakim, Luchman. 2004. Dasar-dasar Ekowisata. Malang : Bayumedia Publishing.

Ratih, D., \& Sondarika, W. (2017). ANALISIS POTENSI DESA DITINJAU DARI SOSIAL BUDAYA KESENIAN TRADISIONAL RONGGENG GUNUNG DALAM MENINGKATKAN PENDAPATAN MASYARAKAT PRASEJAHTERA (Studi kasus di desa Ciulu Kec. Banjarsari Kab. Ciamis Jawa Barat). Jurnal Artefak, 4(2), 161-166.

Ross, Glenn F. 1998. Psikologi Pariwisata. Jakarta : Penerbit Yayasan Obor Indonesia.

Soleh, A. (2017). STRATEGI PENGEMBANGAN POTENSI DESA. Jurnal Sungkai, 5(1), $32-52$.

Spillane, James. 1994. Pariwisata Indonesia : Siasat Ekonomi dan Rekayasa Kebudayaan.

Yoeti, Oka A. 1996. Pengantar Ilmu Pariwisata. Edisi Revisi. Bandung : Angkasa. 
Yogyakarta : Kanisius. Hirawan-Shandika. 2008. Analisis Dampak Sosial Pariwisata di Indonesia. Artikel. Maret 2009. 